\title{
Suelo urbano, planeamiento urbanístico y derecho transitorio en la Ley de Ordenación Urbanística de Andalucía ${ }^{1}$
}

\author{
Ínigo del Guayo Castiella
}

Catedrático de Derecho Administrativo

Universidad de Almería

\begin{abstract}
SUMARIO: I. INTRODUCCIÓN; II. EL SUELO URBANO Y LAS REGLAS DE LÓGICA; III. PLANEAMIENTO Y SUELO URBANO; IV. PLANEAMIENTO, SUELO URBANO Y DERECHO TRANSITORIO: 1.- Clasificación y categorización del suelo urbano, planeamiento y derecho transitorio; 2.- Breve referencia a la naturaleza de las Delimitaciones de Suelo Urbano; 3.- La aplicación inmediata e íntegra de la clasificación de suelo urbano contenida en la LOUA; 4.- Vigencia y ejecutividad de los planes e instrumentos vigentes; 5.Nuevas Delimitaciones de Suelo Urbano en municipios sin planeamiento; 6.Planes urbanísticos aprobados inicialmente; V. CONCLUSIONES.
\end{abstract}

\section{INTRODUCCIÓN}

El presente estudio aborda tres cuestiones distintas, pero relacionadas entre sí, de manera que el análisis del concepto de suelo urbano se hace desde

\footnotetext{
${ }^{1}$ Abreviaturas utilizadas: Art.: artículo; BOE: Boletín Oficial del Estado; BOJA: Boletín Oficial de la Junta de Andalucía; BOP: Boletín Oficial de la Provincia; CCAA: Comunidades Autónomas; DSU(s): Delimitación(es) de Suelo Urbano; DT(s): Disposición(es) Transitoria(s); ED(s): Estudio(s) de Detalle; FJ: Fundamento Jurídico; ISG: Instrucción núm. 1/2003, de marzo de 20003, de la Secretaría General de Ordenación del Territorio y Urbanismo en relación con la entrada en vigor de y aplicación de la LOUA; LAS: Ley núm. 1/1997, de 18 de junio, por la que se adoptan con carácter urgente y transitorio en Andalucía disposiciones en materia de Régimen del Suelo y Ordenación Urbana; LOUA: Ley núm. 7/2002, de 17 de diciembre, de Ordenación urbanística de Andalucía; LRJPAC: Ley núm. 30/1992, de 26 de noviembre, de Régimen Jurídico de las Administraciones Públicas y del Procedimiento Administrativo Común; LRSV: Ley núm. 6/1998, de 13 de abril, de Régimen del Suelo y Valoraciones; NNSS: Normas Subsidiarias de Planeamiento Municipal; PE(s): Plan(es) Especial(es); PGOU(s): Plan(es) General(es) de Ordenación Urbanística; POI(s): Plan(es) de Ordenación Intermunicipal; PPO(s): Plan(es) Parcial(es) de Ordenación; PS(s): Plan(es) de Sectorización; RPU: Reglamento de Planeamiento, aprobado mediante Real Decreto núm. 2159/1978, de 23 de junio; STC: Sentencia del Tribunal Constitucional; TC:
} 
la consideración que ese tipo de suelo tiene en el planeamiento urbanístico y ambos aspectos, a su vez, son considerados a partir del tratamiento que el derecho transitorio de la LOUA otorga tanto al suelo urbano como al planeamiento.

La LOUA entró en vigor el 20 de enero de $2003^{2}$ y algunas de las cuestiones que planteaba el derecho transitorio son ya derecho histórico, pero hay que reconocer que en España, por distintas características propias de la vida nacional, el derecho histórico (incluyendo el derecho positivo derogado) suele gozar de larga vida, pues tanto las Administraciones Públicas como, sobre todo, los tribunales de justicia, han de enjuiciar situaciones generadas por unas normas que ya no están vigentes o cuya vigencia se ideó para permitir un tránsito justo y no traumático de un sistema jurídico a otro. Por lo demás, el derecho transitorio de la LOUA tiene una especial vocación de futuro, pues no se impone propiamente un plazo máximo para llevar a cabo la adaptación de los instrumentos de planeamiento a la ley, de manera que las previsiones del derecho transitorio adquieren actualidad de modo recurrente ${ }^{3}$. Los problemas interpretativos de la LOUA son muchos y variados, y más aún los que suscita el derecho transitorio, en particular las DTs que afectan más directamente al suelo urbano ${ }^{4}$, y de algunos de esos problemas voy a ocuparme en estas páginas.

\section{EL SUELO URBANO Y LAS REGLAS DE LA LÓGICA}

La clasificación del suelo es un presupuesto imprescindible o premisa indispensable para la igualación de las condiciones básicas del ejercicio del de-

Tribunal Constitucional; TRLS: Real Decreto Legislativo núm. 1/1992, de 26 de junio, por el que se aprobó el Texto Refundido de la Ley sobre el Régimen del Suelo y Ordenación Urbana; TRLS76: Real Decreto núm. 1346/1976, de 9 de abril, que aprueba el Texto Refundido de la Ley sobre Régimen del Suelo y Ordenación urbana.

${ }^{2}$ Fue publicada BOJA núm. 154, de 31 de diciembre de 2002 y BOE núm. 12, de 14 de enero de 2003. Para su entrada en vigor se toma en consideración la publicación en el BOJA, con una vacatio legis de 20 días.

${ }^{3}$ Vid. Fernández Fernández, G.-R., Los instrumentos de ordenación urbanística. El planeamiento general y las normativas directoras de ordenación urbanística, en Guayo Castiella, I. del y Martínez García, S., «Derecho Urbanístico de Andalucía», ed. Marcial Pons, Madrid 2003, pp. 101-121, particularmente p. 120.

${ }^{4}$ DTs $1^{\underline{a}}$ a $5^{\underline{a}}$ y $7^{7}$ 
recho de propiedad y, por tanto, pertenece también a la competencia del Esta$\mathrm{do}^{5}$, cuya norma clasifica el suelo, a los efectos exclusivos de la $\mathrm{LRSV}^{6}$ (es decir, como presupuesto de esa igualdad), en urbano, urbanizable y no urbanizable (o clases equivalentes reguladas por la legislación urbanística autonómica), de acuerdo, en el caso del suelo urbano, con unos criterios de tipo material, pues para la LRSV es suelo urbano, en primer lugar, el suelo ya transformado por contar, como mínimo, con acceso rodado, abastecimiento de agua, evacuación de aguas y suministro de energía eléctrica ${ }^{8}$ (cuatro servicios que, tradicionalmente en nuestro Derecho, han servido para determinar cuándo un suelo está urbanizado); en segundo lugar, es suelo urbano aquel suelo que esté consolidado por la edificación en la forma y características que establezca la legislación urbanística (autonómica) ${ }^{9}$; y, en tercer lugar, forman parte del suelo urbano los terrenos que hayan sido urbanizados en ejecución y de acuerdo con el planeamiento ${ }^{10}$. En relación con los dos primeros criterios conviene aclarar, en primer lugar, que la presencia de los cuatro servicios mencionados no significa que el suelo esté urbanizado, sino transformado, un matiz importante, pues, por una parte, sólo a las CCAA corresponde determinar cuándo un suelo ha de considerarse urbanizado y, por otra, la LOUA viene a corroborar que la existencia de esos servicios no significa que el suelo esté urbanizado $^{11}$; y, en segundo lugar, conviene aclarar que la expresión consolidado por la edificación no debe conducir al error de pensar que esos terrenos forman parte ni del llamado suelo urbano consolidado ni del no consolidado, dos categorías de suelo urbano al que me

\footnotetext{
${ }^{5}$ SSTC núm. 61/1997, de 20 de marzo y núm. 164/2001, de 11 de julio. La segunda afirma, en concreto, lo siguiente: «el art. 7 de la LRSV tiene perfecto encaje en la competencia del Estado ex art. 149, 1, 1, de la CE, en los términos ya expresados en la STC núm. 61/1997, FFJ núms. 14, b y 15, a. Entonces amparamos la clasificación tripartita del suelo por su carácter instrumental respecto de la regulación de las condiciones básicas del ejercicio del derecho de propiedad urbana. Y añadimos también entonces que del simple establecimiento de una clasificación tripartita del suelo no podía deducirse la prefiguración por el legislador estatal de un concreto modelo urbanístico». Vid., también, el FJ núm. 13 de la STC núm. 164/2001, de 11 de julio.

${ }^{6}$ Art. 8 LRSV.

${ }^{7}$ Art. 7 LRSV.

${ }^{8}$ Art. 8, letra a, primera frase, LRSV.

${ }^{9}$ Art. 8, letra a, segunda frase, de la LRSV.

${ }^{10}$ Art. 8, letra b, de la LRSV.

${ }^{11}$ Art. 45, 2, letra A, a contrario sensu.
} 
refiero a continuación, sin perjuicio de que adelante que el que la LRSV llama suelo urbano por estar consolidado por la edificación ${ }^{12}$ es una categoría de suelo urbano que responde normalmente al fenómeno del crecimiento de la actividad de edificación sin una urbanización suficiente y de que, por tanto, normalmente será un suelo urbano no consolidado por la urbanización (pero no necesariamente, al menos desde un punto de vista conceptual).

La LRSV ${ }^{13}$ distingue tres clases de suelo y, dentro del suelo urbano, distingue dos categorías básicas: el suelo consolidado por la urbanización y el suelo urbano que carece de urbanización consolidada, una distinción que la LRSV ni impone a las CCAA -las cuales pueden acogerla o no- ni determina cuándo se está ante una u otra categoría (sólo al legislador autonómico corresponde tal cosa), pero sí de gran relevancia para la configuración del estatuto jurídico de la propiedad del suelo urbano, pues la LRSV sí establece deberes distintos en función de que el suelo urbano esté consolidado por la urbanización o ante un suelo urbano que carece de urbanización consolidada.

La LOUA ${ }^{14}$ acude a similares criterios materiales que la LRSV para definir el suelo urbano y añade un criterio formal, cual es que el suelo urbano es aquel que esté adscrito a esta clase de suelo por el PGOU o el POI, pero téngase en cuenta que hay una vinculación del planeador a una determinada realidad física que no se puede ignorar, y el planeador, por tanto, no podrá dejar de clasificar como urbano el suelo que reúna las características señaladas por las normas y la distinción entre dos tipos de suelo urbano -consolidado y no consolidado- ha de moverse también dentro de los límites de la realidad ${ }^{15}$; y téngase igualmente presente que hay también suelo urbano en municipios que carecen de planeamiento general, es decir, de PGOU o de POI.

12 Art. 8, a, segunda frase, LRSV.

${ }^{13}$ Arts. 7 y 14 LRSV. La distinción no invade las competencias urbanísticas de las CCAA, pues, como ha afirmado la STC núm. 164/2001, de 11 de julio (FJ núm. 19), «sirve, exclusivamente, para definir las facultades y deberes urbanísticos de los propietarios. Del art. 14 LRSV no resulta un deber de distinguir e incluir en el planeamiento esas dos categorías. Menos aún contiene el art. 14 LRSV criterios concretos sobre cuándo el suelo urbano debe considerarse consolidado por la urbanización y cuándo no. En estos términos es claro que la regulación estrictamente patrimonial del art. 14 LRSV en nada limita ni condiciona las competencias urbanísticas de las Comunidades Autónomas».

14 Art. 45 LOUA.

${ }^{15}$ FJ núm. 20 de la STC núm. 164/2001, de 11 de julio. 
Integran el suelo urbano, en primer lugar, los suelos que formen parte de un núcleo de población existente o sean susceptibles de incorporarse a él en ejecución del PGOU (ó, en su caso, del POI) y que, unos y otros, estén dotados, como mínimo, de los servicios urbanísticos de acceso rodado por vía urbana, abastecimiento de agua, saneamiento y suministro de energía eléctrica en baja tensión ${ }^{16}$; en segundo lugar pertenecen al suelo urbano los terrenos que están consolidado por la edificación al menos en las dos terceras partes del espacio apto para la edificación según la ordenación que el planeamiento general proponga y han de estar también integrados en la malla urbana en condiciones de conectar con los cuatro servicios urbanísticos señalados ${ }^{17}$; en tercer lugar, la LOUA clasifica como suelo urbano, en paralelismo con lo señalado por la LRSV, el transformado y urbanizado de acuerdo con el planeamiento urbanístico, añadiendo algo que resulta implícito en la LRSV, cual es que la transformación y la urbanización se lleven a cabo de conformidad con las determinaciones de ese plan ${ }^{18}$. De acuerdo con las tres características mencionadas, podría pensarse que en la LOUA el suelo urbano (al menos un tipo de suelo urbano) es el suelo que se reputa urbanizado porque dispone de esos cuatros servicios, pero esto no es así, algo que se percibe claramente cuando se consideran las cuatro ideas siguientes:

a) en primer lugar, cuando la LOUA introduce la distinción entre el suelo urbano consolidado y el suelo urbano no consolidado afirma que el suelo urbano consolidado está formado por los terrenos que tienen alguna de las tres características mencionadas y están urbanizados o tienen la condición de solar ${ }^{19}$ de donde se colige que un terreno no se considera urbanizado porque tenga esos cuatro servicios, aunque sí se considera urbano por esa razón;

b) en segundo lugar, no hay equiparación entre solar y suelo urbano consolidado, aunque la LOUA parezca identificar ambas cosas en algún momento; la LOUA ${ }^{20}$ dice que tienen la condición de solar, a los efectos de la Ley, las

\footnotetext{
${ }^{16}$ Art. 45, 1, letra a, LOUA. Se trata de una definición similar a la del art. 8, letra a, primera frase, de la LRSV, pero adviértanse las tres siguientes diferencias: en primer lugar, que el acceso rodado lo ha de ser "por vía urbana»; en segundo lugar, que habla de saneamiento en lugar de «evacuación de aguas»; y, en tercer lugar, que el suministro de energía eléctrica lo ha de ser «en baja tensión».

${ }^{17}$ Art. 45, 1, letra b, LOUA, en relación con el art. 8, letra a, segunda frase, LRSV.

${ }^{18}$ Art. 45, 1, letra c, LOUA, en relación con el art. 8, letra b, LRSV.

${ }^{19}$ Art. 45, 2, letra A, LOUA.

${ }^{20}$ Art. 148, 4, LOUA.
} 
parcelas de suelo urbano que estén dotadas de los servicios y características que determine la ordenación urbanística, y como mínimo de acceso rodado por vía urbana pavimentada, suministro de agua potable y energía eléctrica con caudal y potencia suficiente para la edificación, construcción e instalación prevista, evacuación de aguas residuales a la red pública y que tengan señaladas alineaciones y rasantes, si existiera planeamiento ${ }^{21}$; el solar está ya completamente urbanizado y nada es ya necesario realizar en él para proceder a la edificación, y en esto se diferencia de la parcela, pues en las parcelas resta aún alguna obra para que se transformen en solares ${ }^{22}$; podría pensarse que la secuencia lógica es la siguiente: i) el suelo es urbano cuando dispone de acceso rodado por vía urbana, abastecimiento de agua, saneamiento y suministro de energía eléctrica en baja tensión ${ }^{23}$, es decir cuando existen en él los servicios urbanísticos mínimos para que el suelo sea considerado como urbano; ii) si, además, el acceso está pavimentado, el suministro de agua y de electricidad tienen caudal y potencia suficiente para la edificación, construcción e instalación previstas, si la evacuación de agua es a la red pública y si -habiendo planeamiento- tiene señalados alineaciones y rasantes, entonces, ese suelo está urbanizado (en sentido estricto), tiene urbanización consolidada y, al mismo tiempo, es un solar edificable; iii) el concepto de solar, por tanto, coincide con el concepto de suelo consolidado y con el de urbanización consolidada y, por tanto, en la expresión cuando estén urbanizados o tengan la condición de solares, la preposición «o» no establecería una disyuntiva, sino una equivalencia; todo sería así más fácil de entender, pero hay un argumento que hace que esa secuencia lógica quiebre, pues cuando se lleva hasta el final el resultado es que crece indebidamente el número de terrenos que han de considerarse como suelo urbano no consolidado a costa del descenso del número de terrenos que han de considerarse como suelo urbano consolidado, con los perjuicios que tal cosa supone para los propietarios de esos terrenos; en efecto, si se identifica el suelo urbano consolidado con el concepto de solar, entonces todo suelo que precise de alguna operación de mejora, renovación o rehabilitación, para que el suelo adquiera la condición de solar, debería ser considerado como suelo urbano no consolidado; sin embargo, sería esa una consecuencia no querida ni por el autor de la LRSV ni por el autor de la LOUA; para el autor de la LRSV -norma que contiene, recuérdese, las condiciones básicas para la

${ }^{21}$ De modo similar al concepto de solar que establecían el art. 82 del TRLS76 y el art. 14 del TRLS.

${ }^{22}$ Art. 149, 2, LOUA.

${ }^{23}$ Art. 45, 1, letra a, LOUA. 
garantía de la igualdad en el ejercicio del derecho de propiedad- uno de los deberes de los propietarios de suelo urbano consolidado por la urbanización es completar a su costa la urbanización necesaria para que los terrenos alcancen -si aún no la tuvieran- la condición de solar ${ }^{24}$; ese deber debe corresponderse normalmente con un derecho, el derecho del propietario de suelo urbano consolidado para completar la urbanización y que el terreno adquiera la condición de solar y, por tanto, el derecho a que su suelo no sea categorizado como urbano no consolidado por el mero hecho de que tenga que llevar a cabo algunas operaciones urbanizadoras; podría pensarse, en la lógica de las Sentencias constitucionales que han abordado las competencias estatales y autonómicas sobre la materia, que la LRSV no está imponiendo a las CCAA ni que identifiquen suelo consolidado con solar ni lo contrario, de manera que la LRSV, en este punto, estaría limitándose a imponer un deber a los propietarios de suelo urbano consolidado (correlativo con un derecho), siempre que la legislación autonómica no identifique suelo consolidado con solar, pues cuando la norma autonómica identifica ambos conceptos, ni existe el deber ni el derecho a completar la urbanización para que el terreno adquiera la condición de solar; pues bien, tanto si se niega que, en ese caso, el deber impuesto por la LRSV no implica un correlativo derecho, como si se acepta que la LRSV no puede imponer a las CCAA que acojan la distinción entre suelo consolidado y solar, lo cierto es que la LOUA no contiene en realidad tal identificación, sino que, muy al contrario, admite expresamente que se lleven a cabo en el suelo urbano consolidado operaciones de urbanización para que los terrenos adquieran la condición de solar. Entre otros lugares en que eso se dice así, está el art. 98, 4, LOUA, que dispone lo siguiente:

«En suelo urbano consolidado, cuando las obras de urbanización necesarias y preceptivas para la edificación de los solares se refieran a la mera reparación, renovación o mejora en obras o servicios ya existentes, la definición de los detalles técnicos de las mismas podrá integrarse en el proyecto de edificación como obras complementarias».

El precepto trascrito demuestra que no se puede identificar suelo consolidado con solar e ilustra acerca de que el suelo urbano pertenece a la categoría del no consolidado cuando la mejora o renovación ha de ser llevada a cabo mediante una actuación integrada de reforma interior, pero no cuando la urbanización requiere una simple mejora o renovación, pues, en ese caso, el suelo urbano pertenece a la categoría del suelo urbano consolidado. En definitiva, no es lo mismo

${ }^{24}$ Art. 14, 1, LRSV. 
que un terreno esté consolidado por la urbanización que tenga la condición de solar, si bien todo terreno que tenga la condición de solar ha de entenderse comprendido dentro del suelo urbano consolidado por la urbanización ${ }^{25}$.

Otro argumento adicional en contra de la identificación en la LOUA del suelo urbano consolidado y el terreno que tiene la naturaleza de solar lo proporciona el art. 56 LOUA $^{26}$, un precepto que sujeta el régimen jurídico del suelo urbano consolidado al régimen jurídico del suelo urbano no consolidado no incluido en unidades de ejecución (salvo en materia de cesiones y aprovechamiento urbanístico), donde se permite la edificación aun cuando la parcela correspondiente no tenga todavía la condición de solar, cuando, entre otras condiciones, se asuma el compromiso de proceder a la realización simultánea de la urbanización y la edificación.

En consecuencia cuando la LOUA dice que es suelo urbano consolidado el que esté urbanizado o tenga la condición de solar $^{27}$ no puede estar estableciendo una equivalencia, sino una disyuntiva.

c) en tercer lugar, el suelo urbano no consolidado puede disponer de los cuatro servicios mencionados como criterio para considerar que el suelo es urbano y ser todavía reputado como suelo urbano no consolidado, de donde se colige que si la presencia de esos servicios no es suficiente para considerar que ese suelo está urbanizado, mucho menos lo será para considerar que tiene urbanización consolidada; piénsese, además, que se incluyen dentro del suelo urbano no consolidado por carecer de urbanización consolidada no sólo los terrenos que carecen de los servicios mencionados, sino también aquellos que carecen de determinadas infraestructuras y dotaciones básicas ${ }^{28}$; en la LRSV y

\footnotetext{
${ }^{25}$ En la ley urbanística catalana hay una expresa, clara y contundente distinción entre suelo urbano consolidado, solar y suelo urbano no consolidado: arts. 25 a 31 de la Ley núm. 2/2002, de 14 de marzo, de urbanismo (BOE núm. 92, de 17 de abril de 2002). En el ordenamiento urbanístico canario hay una identificación entre suelo urbano consolidado y solar: Villar Rojas, F.J., $E l$ derecho de propiedad del suelo, en «Derecho Urbanístico de Canarias», Instituto de Estudios Canarios, Santa Cruz de Tenerife 2003, pp. 65-96. La afirmación está en p. 90, aunque parece un tanto contradictoria con el hecho que incluya dentro del suelo urbano consolidado los terrenos «localizados en ámbitos en los que quedan pendientes algunas obras de urbanización cuya culminación no precisa equidistribución, ni cesiones».

${ }^{26}$ En relación con el art. 55, 2, letra B, párrafo segundo, LOUA.

${ }^{27}$ Art. 45, 2, letra A, LOUA.

${ }^{28}$ Art. 45, 2, letra B, letra a, 1, LOUA.
} 
en la LOUA no hay correlación sustantiva entre los preceptos que definen qué terrenos deben ser incluidos dentro del suelo urbano con los preceptos que definen las dos categorías de suelo urbano; unos y otros se mueven en dos planos distintos; en efecto, tanto la LRSV como la LOUA mandan que el planeamiento incluya dentro del suelo urbano aquellos terrenos que dispongan de cuatro servicios ${ }^{29}$, pero eso no significa que los terrenos que tengan tales servicios deban ser considerados como suelo urbano consolidado por la urbanización ${ }^{30}$; dicho de otra forma, el art. 45, 1, letra a, LOUA (suelo urbano por contar con los cuatro servicios) no es correlativo con el art. 45, 2, letra A, LOUA (suelo urbano consolidado), pues el carácter consolidado del suelo urbano no deriva de cualquier grado de urbanización, sino de una urbanización cualificada;

d) en cuarto y último lugar, no hay identificación entre suelo urbano consolidado y suelo urbanizado por la sencilla razón que el suelo urbano no consolidado está también urbanizado aunque, podríamos decir, de modo insuficiente $^{31}$.

A la vista de esas cuatro ideas uno se pregunta acerca de los defectos de que adolece el art. 45 LOUA, defectos que generan confusión en el lector. ¿Qué es lo que falla en ese artículo? Uno de los problemas que ofrece este precepto es que no nos dice ni qué entiende por suelo urbanizado ni -en puridad- por suelo urbano consolidado, aunque sí describa el urbano no consolidado, pero lo que verdaderamente falla en el art. 45 son las más elementales reglas de la lógica, pues la urbanización, que es la propiedad del género suelo urbano, es empleada también para definir una de las especies, concretamente la especie suelo urbano consolidado, dentro del género suelo urbano.

De todo lo anterior estamos autorizados a concluir que el suelo urbano consolidado es, en la LOUA, una categoría residual, bien que sin la misma claridad y rotundidad con la cual el autor de la LRSV otorgó al urbanizable un carácter residual respecto del no urbanizable. En efecto, la LOUA considera que forman parte del suelo urbano consolidado los terrenos que están urbanizados o tienen la condición de solares, siempre que no hayan de conside-

\footnotetext{
${ }^{29}$ Art. 8, letra a, LRSV y art. 45, 1, letra a, LOUA.

${ }^{30}$ Una categoría de suelo urbano contemplada en el art. 14, 1, LRSV y que define el art. 45, 2, letra A, LOUA.

${ }^{31}$ Art. 45, 2, letra B, letra a, LOUA.
} 
rarse comprendidos dentro de la categoría de suelo urbano no consolidado ${ }^{32}$. $\mathrm{Si}$, por un lado, no puede decirse que el consolidado sea el suelo urbanizado, y si, por otro lado, tampoco puede decirse que el consolidado sea identificable con el concepto de solar, entonces no hay en la LOUA ninguna definición de suelo urbano consolidado, y se trata de una categoría residual, de manera que es suelo urbano consolidado el que no haya de reputarse como suelo urbano no consolidado.

De acuerdo con la LOUA, los terrenos deben incluirse dentro de la categoría de suelo urbano no consolidado cuando concurren en ellos alguna de las dos circunstancias siguientes ${ }^{33}$ :

En primer lugar, si los terrenos carecen de urbanización consolidada ${ }^{34}$; a su vez, se entiende que los terrenos carecen de urbanización consolidada por alguna de las dos circunstancias siguientes:

a) si la urbanización no tiene todos los servicios, infraestructuras y dotaciones públicos precisos, o si unos u otras no tienen la proporción o las características adecuadas para servir a la edificación que sobre ellos exista o se haya de construir ${ }^{35}$;

b) si la urbanización precisa renovación, mejora o rehabilitación que deba ser realizada mediante actuaciones integradas de reforma interior, incluyendo las actuaciones dirigidas a establecer dotaciones ${ }^{36}$. A este respecto, una de las finalidades de los PEs es establecer la ordenación detallada de las áreas urbanas sujetas a actuaciones u operaciones integradas de reforma interior, para su renovación, mejora, rehabilitación o colmatación ${ }^{37}$.

En segundo lugar, es suelo urbano no consolidado cuando el aprovechamiento objetivo otorgado por el planeamiento a los terrenos que forman par-

\footnotetext{
${ }^{32}$ Art. 45, 2 de la LOUA.

${ }^{33}$ Art. 45 LOUA.

${ }^{34}$ Art. 45, 2, letra B, letra a, LOUA.

${ }^{35}$ Art. 45, 2, letra B, letra a, 1, LOUA.

${ }^{36}$ Art. 45, 2, letra B, letra a, 2, LOUA.

${ }^{37}$ Art. 14, 1, letra c, LOUA.
} 
te de áreas homogéneas de edificación (continuas o discontinuas) sea considerablemente superior al existente, siempre que la ejecución requiera el incremento o mejora de los servicios públicos y de urbanización existentes ${ }^{38}$.

Si bien se mira, todas las circunstancias por las cuales un suelo urbano no se considera consolidado por la LOUA tienen que ver con el grado de urbanización, pues la segunda de esas dos circunstancias no determina que el suelo urbano sea no consolidado sólo por el hecho de que el planeamiento atribuya a los terrenos un aprovechamiento objetivo considerablemente superior al existente, sino cuando, además, la ejecución de ese planeamiento requiere una mejora o incremento de la urbanización (dado que, por lo demás, los servicios públicos a que se está refiriendo el art. 45, 2, letra B, letra b, de la LOUA, deben ser, lógicamente, los cuatro servicios cuya presencia hace que el suelo se considere urbano).

La distinción entre suelo urbano consolidado y suelo urbano no consolidado tiene una especial trascendencia en materia de cesiones obligatorias y gratuitas, pues los propietarios de suelo de la primera categoría no tienen deber de cesión alguno, mientras que los propietarios de suelo de la segunda categoría sí tienen deberes de cesión. A pesar de que se tiene la impresión de que la categoría de suelo urbano no consolidado por tener los terrenos un aprovechamiento objetivo considerablemente superior al existente, busca, en el fondo, imponer determinados deberes de cesión sobre los propietarios de un suelo que debería ser clasificado como urbano consolidado, lo cierto es que la LOUA ha tenido cuidado en añadir que, junto a ese mayor aprovechamiento, debe ser precisa una mejora de la urbanización, de donde se sigue que este supuesto no es, en principio, equiparable al que contemplaba una ley vasca de 1998, que imponía determinados deberes de cesión sobre los propietarios de suelo urbano consolidado, una previsión que fue reputada inconstitucional por la STC núm. 54/2002, de 27 de febrero, si bien algunas afirmaciones del TC podrían avalar, en cierta manera, la inconstitucionalidad de algún apartado del art. 45, 2, letra B, de la LOUA, puesto en relación con el art. 51, letra C, letras d y e, también de la LOUA.

Otra categorización relevante en materia de suelo urbano no consolidado es la que distingue entre el que está incluido en unidades de ejecución y el que no está incluido en unidades de ejecución ${ }^{39}$, distinción de la que se deri-

\footnotetext{
38 Art. 45, 2, letra B, letra b, LOUA.

${ }^{39}$ Art. 55, 1 y 2, respectivamente, LOUA.
} 
van algunas diferencias en el régimen jurídico aplicable ${ }^{40}$. Una última distinción es entre el suelo urbano no consolidado incluido en áreas de reparto y el suelo urbano no consolidado excluido de áreas de reparto, relevante para el cálculo de los porcentajes de aprovechamiento que corresponde al propietario y de los porcentajes de cesión al Municipio ${ }^{41}$.

\section{PLANEAMIENTO Y SUELO URBANO}

La LOUA contempla como instrumentos de planeamiento que afectan a la ordenación urbanística del suelo urbano unos instrumentos de planeamiento general (PGOUs y POIs) y unos planes de desarrollo (PPOs, PEs y EDs).

En relación con el suelo urbano, los PGOUs proceden, en todos los municipios, a clasificar la totalidad del suelo en alguna de las clases y categorías de suelo previstas en la LOUA (dentro de las cuales se encuentran la categoría de suelo urbano consolidado y la de no consolidado) ${ }^{42}$, así como los usos, densidades y edificabilidades globales para las distintas zonas de suelo urbano y para los sectores de suelo urbano no consolidado ${ }^{43}$. El PGOU establece asimismo la ordenación pormenorizada, con algunas determinaciones preceptivas en relación con el suelo urbano consolidado, que son las siguientes ${ }^{44}$ : a) la ordenación urbanística detallada; b) el trazado pormenorizado de la trama urbana; c) espacios públicos; y d) dotaciones comunitarias; estas cuatro determinaciones completan la ordenación estructural que también contiene el

\footnotetext{
${ }^{40}$ Sobre los derechos y deberes de los propietarios de suelo urbano, y sobre el régimen jurídico de dicho suelo, me permito remitir a mi trabajo El Régimen urbanístico de la propiedad del suelo. Régimen jurídico del suelo urbano y urbanizable, en Guayo Castiella, I. del y Martínez García, S., «Derecho Urbanístico de Andalucía», ed. Marcial Pons, Madrid 2003, pp. 142-212, particularmente pp. 170-189.

41 Arts. 55, 2, letra A, y 58, LOUA.

42 Art. 10, 1, letra A, letra a, y art. 44, ambos de la LOUA. De acuerdo con el segundo precepto citado, algunos terrenos destinados a sistemas generales -aquellos que por su naturaleza, entidad u objeto tengan carácter o interés supramunicipal o singular-pueden ser excluidos de tal clasificación (sin perjuicio de su adscripción a alguna de las tres clases de suelo a efectos de su valoración y obtención).

${ }^{43}$ Art. 10, 1, letra A, letra d, LOUA.

${ }^{44}$ Art. 10, 2, letra A, LOUA.
} 
PGOU; la ordenación del suelo urbano consolidado debe igualmente determinar los usos pormenorizados y las ordenanzas de edificación, de manera que se legitime directamente la actividad de ejecución sin necesidad de planeamiento de desarrollo ${ }^{45}$.

Por su parte, en el suelo urbano no consolidado, el PGOU procede a la delimitación de las áreas de reforma interior (sujetas, por tanto, a su ordenación detallada), con definición de sus objetivos y asignación de usos, densidades y edificabilidades globales para cada área. Asimismo, el PGOU delimita las áreas de reparto que deban definirse y se determinarán sus aprovechamientos medios ${ }^{46}$.

Con carácter potestativo, el PGOU puede incluir las mismas determinaciones preceptivas propias del suelo urbano consolidado en todo o en parte del suelo urbano no consolidado, para hacer posible la actividad de ejecución sin ulterior planeamiento de desarrollo ${ }^{47}$; cuando el PGOU proceda a la ordenación detallada del urbano no consolidado, el Plan contendrá también el plazo de ejecución de las distintas áreas o sectores ${ }^{48}$; si el PGOU no fija la ordenación detallada de sectores en suelo urbano no consolidado o en áreas de reforma interior, puede, sin embargo, potestativamente, fijar un plazo máximo para que se proceda a la ordenación detallada de esos sectores ó áreas y, si se han delimitado, para la ejecución de las unidades de ejecución ${ }^{49}$.

Cuando el PGOU no contiene la ordenación detallada para la ejecución integrada de sectores enteros en suelo urbano no consolidado, tal ordenación corresponde a los $\mathrm{PPOs}^{50}$, instrumento por el cual puede también procederse

\footnotetext{
${ }^{45}$ En suelo urbano consolidado, el PGOU es el instrumento de planeamiento que legitima la actividad de ejecución: art. 96, 1, letra a, LOUA.

${ }^{46}$ Art. 10, 2, letra A, letra b. las mismas determinaciones sobre suelo urbano de un PGOU pueden incluirse en un POI, por cuanto la ordenación pormenorizada de suelo urbano perteneciente a dos o varios municipios -sobre todo, el suelo urbano no consolidado periférico- puede resultar adecuada para el cumplimiento de su objeto específico: Art. 11, 3, LOUA, en relación, sobre todo, con el art. 17, 4, LOUA.

${ }^{47}$ Art. 10, 2, letra B, LOUA. Cuando incluye esas determinaciones, el PGOU se convierte en el instrumento que legitima la actuación en el suelo urbano no consolidado: art. 96, 1, letra b.

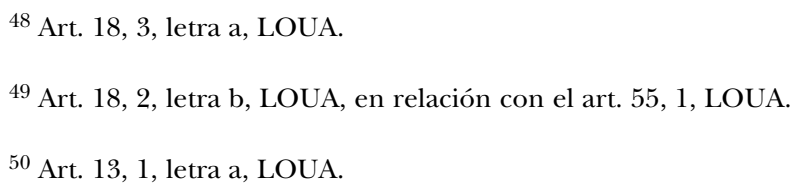


a modificar -para su mejora- la ordenación pormenorizada potestativa del PGOU de sectores enteros del suelo urbano no consolidado (respetando la ordenación estructural, y los criterios y las directrices del PGOU, sin que pueda afectar negativamente a la funcionalidad del sector o a la ordenación de su entorno $)^{51}$.

Dado que el suelo urbano puede tener la consideración de no consolidado porque la urbanización precise una renovación, mejora o rehabilitación que haya de realizarse mediante actuaciones integradas de reforma interior, incluyendo las actuaciones dirigidas a establecer dotaciones ${ }^{52}$, entonces un cauce adecuado para el establecimiento de la ordenación pormenorizada de ese suelo sería un PE, como la propia norma andaluza dice expresamente ${ }^{53}$, pues entre las finalidades de los PEs se encuentran las siguientes, específicamente relativas al suelo urbano, teniendo en cuenta, además, que los PEs pueden modificar el PGOU en sus determinaciones pormenorizadas potestativas (como son las propias del suelo urbano no consolidado $)^{54}$ : a) establecimiento de dotaciones ${ }^{55}$; b) conservación, protección y mejora del medio urbano, especialmente el portador de valores urbanísticos, arquitectónicos, históricos o culturales ${ }^{56}$; y c) la ordenación detallada de las áreas urbanas sujetas a actuaciones $\mathrm{u}$ operaciones integradas de reforma interior, para la renovación, mejora, rehabilitación o colmatación de esas áreas ${ }^{57}$. De estas tres finalidades que, en su caso, pueden tener los PEs, las dos primeras pueden perseguirse tanto en desarrollo de un PGOU como en su ausencia ${ }^{58}$, mientras que la tercera finalidad sólo puede llevarse a cabo en desarrollo de un PGOU ${ }^{59}$. Es ra-

51 Art. 13, 1, letra b, LOUA.

${ }^{52}$ Art. 45, 2, letra B, letra a, 2, LOUA.

${ }^{53}$ Art. 17, 1 y 5; y art. 96, 1, letra b, LOUA.

${ }^{54}$ Art. 14, 3, LOUA.

55 Art. 14, 1, letra a, LOUA.

56 Art. 14, 1, letra b, LOUA.

${ }^{57}$ Art. 14, 1, letra c, LOUA.

58 Art. 14, 1, letras a y b, LOUA, en relación con el art. 14, 2, letras a y b, LOUA.

${ }^{59}$ Art. 14, 1, letra c, LOUA, en relación con el art. 14, 2, letras a y b, LOUA. 
zonable que esto sea así, pues parece lógico que una ordenación detallada del suelo urbano no consolidado tenga que integrarse en la ordenación urbanística más amplia del PGOU, a diferencia del mero establecimiento de una dotación o de la protección de un edificio o de un conjunto histórico-artístico. No se olvide que los PEs pueden tener cualesquiera otras finalidades análogas, pero que habrán siempre de hacerse en desarrollo de un PGOU ${ }^{60}$. Adicionalmente, la LOUA admite que el instrumento legitimador de la actividad de ejecución en el suelo urbano no consolidado, cuando lo sea por estar incluidos esos terrenos en áreas de reforma interior ${ }^{61}$, sea el Estudio de Detalle, lo cual refuerza la nueva naturaleza que este instrumento tiene en Andalucía, como instrumento propio del planeamiento de desarrollo ${ }^{62}$. Los Estudios de Detalle se aprueban siempre en desarrollo de otro planeamiento previo (PGOU, PPOs o PEs) para completar sus determinaciones en áreas de suelos urbanos de ámbito reducido ${ }^{63}$, y en el caso de las áreas de reforma interior, la LOUA parece estar admitiendo que el Estudio de Detalle se apruebe como instrumento legitimador de la actuación en suelo urbano no consolidado, como una alternativa al PGOU, al PPO y al $\mathrm{PE}^{64}$.

Sea cual sea el instrumento que contenga la ordenación del suelo urbano no consolidado (PGOU, PPO o, en su caso, PE), habrá de sujetarse a las reglas sustantivas y estándares de ordenación de la LOUA $^{65}$ si bien se admiten ciertas exenciones, según se prevea reglamentariamente ${ }^{66}$.

En el suelo urbano las unidades de ejecución pueden ser discontinuas, siempre que en ellas se garantice la equidistribución ${ }^{67}, y$, específicamente pa-

\footnotetext{
${ }^{60}$ Art. 14, 1, letra h, LOUA, en relación con el art. 14, 2, letra a, LOUA.

${ }^{61} \mathrm{~A}$ las que se refiere el art. 45, 2, letra B, letra a, 2, LOUA.

${ }^{62}$ Art. 15 LOUA.

${ }^{63}$ Art. 15, 1, LOUA.

${ }^{64}$ Art. 96, 1, letra b, LOUA.

${ }^{65}$ Art. 17, 1, LOUA.

${ }^{66}$ Art. 17, 2, LOUA.

${ }^{67}$ Art. 105, 2, LOUA.
} 
ra el suelo urbano no consolidado se prevé que el efecto de la delimitación de unidades de ejecución se circunscriba a la fijación de un ámbito de sujeción al pago de cuotas y como referencia para la fijación, a su vez, de la base imponible de las contribuciones especiales ${ }^{68}$. También se admite la delimitación de unidades de ejecución que incluyan terrenos pertenecientes al suelo urbano no consolidado y al urbanizable ${ }^{69}$.

\section{PLANEAMIENTO, SUELO URBANO Y DERECHO TRANSITO- RIO}

\section{Clasificación y categorización del suelo urbano, planeamiento y derecho transitorio:}

La LOUA consagra la distinción entre suelo urbano consolidado y no consolidado, si bien esa clasificación estaba ya en la LRSV, pero sin que tales categorías de suelo urbano tuviesen necesariamente que ser acogidas por la normativa urbanística andaluza, algo que finalmente sí ocurrió en Andalucía. La LOUA persigue determinados objetivos y para alcanzarlos diseña, entre otras cosas, diversos instrumentos de planeamiento (básicamente, un planeamiento general y otro de desarrollo), que han de recoger las distintas categorías de suelo. Como la mayoría de las normas, la LOUA se ve en la necesidad de abordar diversos aspectos de derecho transitorio, que se suscitan por el hecho de que la LOUA entra en vigor en un determinado momento, con nuevas previsiones que han de operar a partir de la existencia de un planeamiento y de una actividad de ejecución diseñados de acuerdo con una normativa preexistente y más o menos diferente a la nueva, y el legislador decidió que las determinaciones contenidas en sus Títulos II (régimen urbanístico del suelo), III (instrumentos de intervención en el mercado de suelo), VI (disciplina urbanística) y VII (infracciones urbanísticas y sanciones) fuesen de aplicación íntegra, inmediata y directa ${ }^{70}$. Esta declaración supuso que las previsiones de la LOUA en esos cuatro ámbitos se impusieron, desde su entrada en vigor, sobre todo el planeamiento urbanístico vigente en ese momento, pero la LOUA no procede a derogar esos planes, sino que, por el contrario, proclama expresa-

\footnotetext{
${ }^{68}$ Art. 105, 5, LOUA.

${ }^{69}$ Art. 105, 4, LOUA.

${ }^{70}$ DT $1^{a} \underline{a}, 1$, párrafo $1^{\circ}$, LOUA.
} 
mente su vigencia ${ }^{71}$; para cohonestar la aplicación inmediata y directa de determinadas previsiones con la proclamación de la vigencia de los planes, dispone la LOUA que las normas contenidas en el planeamiento vigente que fueran contradictorias con las normas de la LOUA de aplicación inmediata y directa serán inaplicables y todas las demás normas del planeamiento vigente en el momento de entrada en vigor de la LOUA se interpretarán de conformidad con la LOUA $^{72}$. De estas dos reglas se desprende, por un lado, que sólo son inaplicables las previsiones de los planes urbanísticos que sean contradictorias con las normas de directa e inmediata aplicación de la LOUA, y, por otro lado, que todas las determinaciones de los instrumentos de planeamiento vigentes en el momento de entrada en vigor de la LOUA han de interpretarse de conformidad con la LOUA, ya sean determinaciones relacionadas con las normas de la LOUA de aplicación inmediata y directa, ya sean determinaciones relativas a otros aspectos del urbanismo. Esta regla de interpretación conforme a la LOUA de todo el planeamiento vigente en el momento de entrada en vigor de la ley explica, por ejemplo, que la LOUA determine que todas las unidades de ejecución ya delimitadas se equiparan a las unidades de ejecución previstas en la LOUA y que el aprovechamiento tipo ya fijado sea, a todos los efectos, el aprovechamiento medio, pues aunque los preceptos relativos a la ejecución del planeamiento (Título IV) no han sido declarados de inmediata y directa aplicación, la mencionada regla de interpretación rige en todas las materias urbanísticas.

Aborda igualmente la LOUA otros cinco problemas de derecho transitorio con especial relevancia sobre el planeamiento y el suelo urbano: a) la adaptación de los planes a la $\mathrm{LOUA}^{73}$; b) los planes e instrumentos en curso de ejecución $^{74}$; c) los planes en curso de aprobación ${ }^{75}$; d) los planes que no hubiesen sido aprobados inicialmente ${ }^{76}$; y e) la ordenación urbanística en los municipios sin planeamiento general ${ }^{77}$. Un problema no abordado expresamen-

\footnotetext{
${ }^{71}$ DT $1^{\mathrm{a}}, 1$, párrafo $1^{\mathrm{o}}$, y DT $2^{\mathrm{a}}, 1$, ambas de la LOUA.

${ }^{72}$ DT $2^{a}, 1$, LOUA.

${ }^{73}$ DT $2^{\mathrm{a}}, 2$, LOUA.

${ }^{74}$ DT $3^{\underline{a}}$ LOUA.

${ }^{75}$ DT $4^{\underline{a}}$ LOUA.

${ }^{76}$ DT $5^{\underline{a}}$ LOUA.

${ }^{77}$ DT $7^{\mathrm{a}}$ LOUA.
} 
te por la LOUA es el de la equivalencia entre los planes e instrumentos de planeamiento anteriores a la LOUA y los nuevos planes e instrumentos diseñados en la nueva ley: en este sentido, sí ha de tenerse presente que, en varias ocasiones, la LOUA equipara las NNSS a los PGOUs ${ }^{78}$. Antes de afrontar la relación entre la LOUA y el planeamiento relativo al suelo urbano, pongo de manifiesto que los planes que se estuviesen ya ejecutando pudieron seguir siendo ejecutados de conformidad con la normativa anterior, sin perjuicio de la aplicación inmediata del Título II, sobre el régimen urbanístico del suelo, siempre que se cumpliesen determinadas condiciones ${ }^{79}$. En este sentido, por ejemplo, un suelo urbano que, de acuerdo con los nuevos criterios de la LOUA hubiese de ser considerado como no consolidado, no podrá ser objeto de ejecución de acuerdo con el planeamiento vigente en el momento de entrada en vigor de la LOUA, si no se cumplen, respecto de ese suelo, todas las exigencias propias del régimen jurídico que la LOUA diseña para esa categoría de suelo.

\section{Breve referencia a la naturaleza de las Delimitaciones de Suelo Urbano:}

Dado que algunos de los problemas asociados a la comprensión del derecho transitorio están ligados, a su vez, a las DSUs, incluyo a continuación una breve referencia a su origen y naturaleza.

Los Proyectos de DSU estaban contemplados, inicialmente, en el art. 81 TRLS76, para los municipios carentes de planeamiento general, para que determinasen el suelo que había de tener la condición de urbano, como una mera operación de deslinde, sin ningún carácter normativo o de ordenación; con posterioridad, el art. 3 y los arts. 101 a 103 del RPU parecieron darle un carácter de instrumento de ordenación o planeamiento ${ }^{80}$, y con tal carácter normativo o de ordenación pasó al art. 81 TRLS, que permitía que el Proyecto de DSU contuviese alineaciones del sistema viario existente, completando con las que fueren procedentes las insuficiencias de dicho sistema, así como la reglamentación de las condiciones de la edificación, mediante las correspondientes ordenanzas. La mejor doctrina, empero, ha negado siempre la naturaleza

${ }^{78}$ DT $4^{\mathrm{a}}, 3$, y DT $5^{\underline{a}}$, ambas de la LOUA.

${ }^{79}$ DT $3^{\mathrm{a}}$ LOUA.

${ }^{80}$ Las DSUs están también contempladas en el Real Decreto-Ley núm. 16/1981, de 16 de octubre, de adaptación de Planes Generales de Ordenación Urbana (BOE núm. 253, de 22 de octubre de 1981): arts. 2, 2 y 3; y 3, con una eficacia meramente supletoria en Andalucía. 
normativa del Proyecto de DSU ${ }^{81}$. Declarado nulo el art. 81 TRLS por la STC núm. 61/1997, de 20 de marzo ${ }^{82}$, por su carácter supletorio de la legislación autonómica, pasó al ordenamiento andaluz en virtud de la LAS.

En las disposiciones sustantivas de la LOUA, la DSU, sencillamente, no existe, no está contemplada y, por tanto, no es un instrumento de planeamiento general ni tampoco tiene la naturaleza del planeamiento de desarrollo; por tanto, no es un instrumento para la ordenación urbanística ${ }^{83}$, pues ha de entenderse que los instrumentos de planeamiento son sólo aquellos que enumera el Capítulo II de la LOUA -ya sean instrumentos de planeamiento general, ya sean planes de desarrollo-, con carácter de enumeración numerus clausus. Como tales, las DSUs no están mencionadas -insisto- en ningún lugar de la LOUA, salvo, precisamente, en las DTs $1^{\underline{a}}, 2^{\underline{a}}$ y $7^{\underline{a}}$, lo cual pone de manifiesto que el derecho más transitorio entre todo el derecho transitorio de la LOUA es el relativo a las DSUs, en la medida en que son instrumentos llamados, de alguna manera, a desaparecer y a ser sustituidas por un

${ }^{81}$ Fernández Rodríguez, T.-R., Manual de Derecho Urbanístico, Abella El Consultor, Madrid 2000, pp. 77-78; en el mismo sentido, Jalvo Minguez, J. y Santos Diez, R., Planeamiento urbanístico, en «Manual de Urbanismo», INAP, Madrid 2001, pp. 97-231. La idea está en p. 182.

${ }^{82}$ Así como la DT 8 ${ }^{\mathrm{a}}$ TRLS; FJ 42: la impugnación se «dirige contra la Disposición transitoria octava relativa al suelo urbano en Planes sin adaptar por imponer como básico no sólo una necesaria aprobación de la delimitación del suelo urbano, sino las reglas a que ésta deba someterse. En cuanto al primer punto, debe precisarse que el Estado puede, desde luego, disponer que las prescripciones básicas sean atendidas desde el momento de la entrada en vigor de la ley (como hace, v. gr., la Disposición transitoria primera del TRLS). Lo que no puede, sin embargo, es introducirse en las técnicas o instrumentos concretos a través de los cuales deba articularse esa efectividad, como pretende el primer párrafo de la Disposición aquí impugnada, al señalar que 'requerirá la aprobación de la delimitación del suelo urbano'. Igual conclusión se alcanza respecto de la determinación de las concretas reglas a las que habrá de someterse la aprobación de la delimitación del suelo urbano, pues es éste un tema que escapa también a las competencias estatales, máxime si tenemos en cuenta que los preceptos a los que se remite [expresamente, art. 10, a); implícitamente, 118.3, a), TRLS, entre otros] no tienen carácter básico ni pueden tenerlo. Obligado es concluir, pues, en la inconstitucionalidad por incompetencia de la Disposición transitoria octava».

${ }^{83}$ Así lo expresa la ISG (p. 8): «La LOUA establece que el PGOU es la única figura de ordenación general de la totalidad del Municipio. Por tanto, no está considerando a la DSU como tal figura, sino que orienta hacia su sustitución por un PGOU». Esta instrucción se aplica en cumplimiento de la DT 2ạ , 2, Párrafo 3, LOUA, que dice lo siguiente: «La Consejería competente en materia de urbanismo, con la finalidad de contribuir a una adecuada adaptación de los planes a esta legislación, podrá aprobar instrucciones orientativas sobre el contenido, plazos y alcance de dichas adaptaciones». 
PGOU $^{84}$, sin perjuicio de que destaquemos, por un lado, que las DSUs contempladas en las DTs pueden tener cierto carácter normativo y, por otro lado, que no se trata de instrumentos preexistentes a la LOUA que la propia LOUA congele, pues, en primer lugar, las DSUs existentes conservan su vigencia hasta su revisión o su total cumplimiento o ejecución ${ }^{85}$; en segundo lugar, pueden los municipios que cuenten con un PGOU, unas NNSS o una DSU o a la entrada en vigor de la LOUA aprobar una DSU de suelo urbano consolida$\mathrm{do}^{86} ; \mathrm{y}$, en tercer lugar, se contempla la aprobación de una DSU en aquellos municipios que, a la entrada en vigor de la LOUA, carezcan de planeamiento general $^{87}$. En resumidas cuentas, hemos de analizar dos tipos de DSUs: en primer lugar, las que se aprueban en municipios que ya contasen, en el momento de entrada en vigor de la LOUA, de un PGOU, unas NNSS o una DSU; y, en segundo lugar, las que se aprueben para municipios que no contasen, en el momento de entrada en vigor de la LOUA, de planeamiento general.

${ }^{84}$ La ISG dice que la LOUA «orienta hacia su sustitución por un PGOU» (p.8). También afirma que las nuevas DSUs contempladas en la DT $7^{\underline{a}}$ se aprobarán con carácter previo a la adaptación a la LOUA (se entiende, con carácter previo a la aprobación de un PGOU) (p. 2).

${ }^{85}$ DT 2a , 1, Primer párrafo. Dice, al final, «conforme a las previsiones de ésta», y ha de reputarse que se trata de una deficiente redacción, pues parece que está diciendo conforme a las previsiones de la LOUA, lo cual, si fuese cierto, sería contradictorio con otras previsiones de derecho transitorio de la LOUA, que contemplan la ejecución de los planes de acuerdo con las previsiones de la normativa urbanística vigente en el momento de entrada en vigor de la LOUA.

${ }^{86}$ DT $1^{a}, 1,1^{a}$, letra a, párrafo $2^{\circ}$, LOUA.

${ }^{87}$ DT $7^{\text {a }}$ LOUA. Otros ordenamientos urbanísticos sí procedieron a congelar la figura de la DSU. Así, la Ley núm. 8/1985, de 4 de diciembre, de la Comunidad de Madrid dejó sin efectos las DSUs reguladas por el Real Decreto-Ley núm. 16/1981. Por su parte, la Ley núm. 9/1999, de 14 de mayo, de Ordenación del Territorio de Canarias (Boletín Oficial de Canarias, núm. 61, de 14 de mayo de 1999) contenía una DT $6^{\underline{a}}$ que disponía lo siguiente: «Municipios sin planeamiento general. En los municipios que no cuenten con planeamiento general de ordenación, regirán, mientras no se apruebe éste, las siguientes reglas: a) Se aplicará inmediatamente la presente Ley; b) La totalidad del término municipal se clasificará exclusivamente en suelo urbano y rústico. Integrarán el suelo urbano los terrenos así clasificados en virtud de un Proyecto de Delimitación de Suelo Urbano aprobado definitivamente con anterioridad a la entrada en vigor de la presente Ley. Todos los demás terrenos pertenecerán al suelo rústico de Protección Territorial, salvo los de Espacio Natural Protegido, que se clasificarán como suelo rústico de protección natural y, en su caso, los sectores de suelo urbanizable estratégico (...)». El Decreto Legislativo núm. 1/2000, de 8 de mayo, por el que se aprueba el Texto Refundido de las Leyes de Ordenación del Territorio de Canarias y de Espacios Naturales de Canarias (Boletín Oficial de Canarias, núm. 60, de 15 de mayo de 2000), deroga aquella Ley, y contiene una DT $6^{\underline{a}}$ en todo igual a la de la ley derogada, pero, lógicamente, la DSU considerada es aquella que hubiese sido aprobada con anterioridad a la entrada en vigor de la Ley núm. 9/1999. 
Hay varias previsiones en el propio derecho transitorio de la LOUA y en el derecho estatal supletorio (vigente y derogado), que otorgan a las DSU un tratamiento parecido al de los instrumentos de planeamiento propiamente dichos, es decir, que gozan de un cierto carácter normativo ${ }^{88}$, y esta circunstancia ha de ser tenida en cuenta a la hora de interpretar y aplicar el derecho transitorio de la LOUA.

\section{La aplicación inmediata e íntegra de la clasificación de suelo urbano conte- nida en la LOUA:}

De acuerdo con la norma urbanística andaluza, desde la entrada en vigor de la LOUA es de aplicación íntegra, inmediata y directa, entre otros, el Título II de la LOUA, relativo al régimen urbanístico del suelo y, en consecuencia, tiene la consideración de suelo urbano consolidado el que cumpla con las condiciones indicadas en la LOUA, cuando se cumplan estas tres condiciones: i) que el municipio disponga de PGOU, NNSS o DSU; ii) cuente con ordenación pormenorizada que permita la edificación y iii) que la ejecución no requiera la delimitación de unidades de ejecución; el resto del suelo clasificado como urbano a la entrada en vigor de la LOUA tiene la consideración de suelo urbano no consolidado ${ }^{89}$.

Si el PGOu o las NNSS en vigor ya distinguían entre suelo urbano consolidado y no consolidado, se presume que esa delimitación se adapta al régimen urbanístico establecido por la LOUA, una presunción que es iuris tantum y que es independiente de que ambas categorías de suelo urbano deban delimitarse en el necesario proceso de adaptación del Plan a la Ley (o, con carácter previo en su caso, mediante la formulación de una DSU de suelo consolidado) ${ }^{90}$.

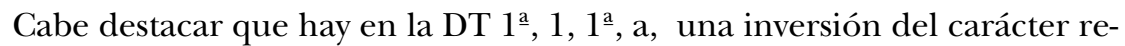
sidual del suelo urbano consolidado respecto del no consolidado, un carácter que puede deducirse de la propia LOUA ${ }^{91}$ y que la ISG acepta, pues en su peculiar interpretación aclaratoria del derecho transitorio viene a decir lo con-

\footnotetext{
${ }^{88}$ Por ejemplo, la DT 1aㅗ $1,11^{a}$, letra a, LOUA.

${ }^{89}$ DT $1^{\mathfrak{a}}, 1,1 \stackrel{\text { a }}{ }$, letra a, primer párrafo, LOUA.

${ }^{90}$ ISG, p. 2.

${ }^{91}$ Art. 45, 2, letra A, LOUA.
} 
trario, que esa DT es decir, que mientras no se proceda a elaborar una DSU del suelo consolidado, tal categoría de suelo es residual respecto del suelo no consolidado, como claramente se aprecia de la lectura del párrafo siguiente:

«En el resto de los casos del planeamiento ya aprobado, en los que no se han delimitado estas categorías de suelo urbano, a los efectos de la aplicación de los contenidos de la Ley en las actuaciones de desarrollo y ejecución del plan, mientras no se produzca esta delimitación por los procedimientos descritos, la interpretación debe ser ajustada a lo dispuesto en la disposición transitoria primera $1.1^{\mathrm{a}}$.a) considerándose integrados en el suelo urbano no consolidado los suelos de las Unidades de Ejecución y los que con claridad y de forma justificada cumplan lo señalado en el artículo 45.2.B.a) y b). En este sentido, es conveniente una aplicación asimilable y homogénea en toda Andalucía sobre las condiciones derivadas del artículo 45.2.A» ${ }^{92}$.

Son tres los requisitos exigidos para que el suelo tenga la condición de suelo urbano consolidado, que se exigen de modo acumulativo y no alternativo. El primero es, como sabemos, que el municipio cuente con PGOU, NNSS y DSUs, de donde se desprende que el autor de la LOUA está otorgando de alguna manera a las DSUs mencionadas en la DT $1^{\underline{a}}, 1,1^{\underline{a}}$, letra a, unos efectos equivalentes a los instrumentos de planeamiento propiamente dichos, al vincular la clasificación del suelo dentro de la categoría de suelo urbano a la existencia de un PGOU, unas NNSS o unas DSUs. La segunda condición -relativa a que el suelo cuente con una ordenación pormenorizada que permita la edificación- es, de algún modo, tautológica, pues de acuerdo con el derecho anterior a la LOUA tanto el PGOU como las $\mathrm{NNSS}^{93}$ debían contener la ordenación pormenorizada del suelo urbano, salvo que se tratase de áreas remitidas a planeamiento especial, es decir, fundamentalmente, a Planes Especiales de Reforma Interior ${ }^{94}$. Puede decirse, por tanto, en principio, que será suelo urbano consolidado de acuerdo con la LOUA todo aquel suelo urbano para cuya ordenación pormenorizada el planeamiento en vigor no haya remitido a un PE (de esta forma volveríamos al carácter residual que el consolidado tiene respecto del no consolidado en el art. 45 LOUA), pero adviértase que esta regla no rige a la inversa, pues no todo suelo para cuya ordenación se haya

\footnotetext{
${ }^{92}$ ISG, p. 2.

${ }^{93}$ Arts. 72, 3, letra A, letra b y f; y art. 77, letra a, TRLS, respectivamente.

${ }^{94}$ Arts. 84, 2, letra c, TRLS y art. 85 TRLS.
} 
previsto un planeamiento de desarrollo, como un PE, ha de considerarse como suelo urbano no consolidado, como por ejemplo, en los PEs cuyo objeto sea la ordenación de recintos y conjuntos histórico-artísticos ${ }^{95}$. Adviértase, sin embargo, que el concepto de suelo urbano no consolidado de la LOUA es más amplio que el concepto de suelo urbano que precisa una actuación integrada de reforma interior y que, por tanto, puede que haya otros suelos urbanos no consolidados en el municipio. De todas maneras, al referirse la LOUA a que el suelo será urbano consolidado cuando cuente con «ordenación pormenorizada que permita la edificación", parece estar dando a entender que identifica los terrenos que integran el suelo urbano consolidado con los terrenos que tengan la condición de solar, pero ya hemos visto que tal cosa ni es ni puede ser así, pues en ningún caso puede interpretarse que cuando el suelo urbano requiera algunas obras para completar la urbanización ese suelo no pueda considerarse como suelo urbano consolidado, por aplicación tanto del art. 14 LRSV como de los art. 56 y 98, 4, LOUA.

Además de proporcionar criterios para la aplicación de la clasificación y categorización del suelo urbano en el planeamiento existente (PGOUs, NNSS o DSUs), añade la LOUA que el municipio podrá redactar una DSU del suelo consolidado, «sin perjuicio» de la aplicación directa de la nueva clasificación y categorización del suelo urbano de la LOUA ${ }^{96}$. La expresión «sin perjuicio» de la DT 1a , 1, 1르, letra a, segundo párrafo, significa que dado que la definición de suelo urbano se encuentra en el Título III de la LOUA, y dado que ese Título es de aplicación íntegra, inmediata y directa, entonces la fijación de los límites del suelo urbano consolidado o la modificación, en su caso, de la DSU existente -que debe contraerse a fijar el suelo urbano consolidado dentro del suelo urbano- debe hacerse de acuerdo con los criterios del art. 45 LOUA. He de señalar que al prever que mediante una DSU se proceda exclusivamente a la delimitación del urbano consolidado, el autor de la LOUA parece olvidar algunas determinaciones sustantivas -no de derecho transitorio- de la LOUA,

\footnotetext{
95 Art. 14, 1, letra b, LOUA. En este sentido, la ISG, p. 3, dice lo siguiente: «Se entiende oportuno aclarar que en algunos casos en que el Plan General, o la Norma Subsidiaria, prevé algún planeamiento de desarrollo, no necesariamente está estableciendo la categoría de suelo urbano no consolidado. Es, por ejemplo, el caso en el que determina la necesidad de redactar un Plan Especial para la protección e intervención en los centros históricos; no debe considerarse el conjunto de éste como no consolidado, sino exclusivamente las zonas o ámbitos para los que, en su caso, se delimite una Unidad de Ejecución o cumplen de forma clara con lo señalado en el artículo 45.2.B.a) y b)».
}

${ }^{96}$ DT 1aa $, 1,1 \underline{a}$, letra a, segundo párrafo, LOUA. 
como la que obliga a que el PGOU identifique como sectores las superficies de suelo urbano no consolidado que tengan una situación periférica o aislada o constituyan vacíos relevantes y resulten idóneas para su ordenación mediante $\mathrm{PPOs}^{97}$. Esa DSU es aprobada por el municipio, tras el trámite de información pública por el plazo de veinte días, y el acuerdo de aprobación será publicado en el BOP y comunicado a la Consejería competente en materia de urbanismo, junto con un ejemplar del documento ${ }^{98}$. ¿Qué naturaleza tiene esta DSU? Parece que esta DSU no pasa de ser una mera delimitación del suelo urbano consolidado, sin ningún elemento de ordenación y, por supuesto, son distintas de las DSUs contempladas en la DT $7^{\underline{a}}$ de la LOUA, pues estas últimas, dice la ISG, son «más amplias que las contempladas en la última parte de la disposición transitoria primera $1.1^{\mathrm{a}} \mathrm{a}{ }^{9}{ }^{99}$. Que esta DSU de suelo urbano consolidado contemplado en la LOUA ${ }^{100}$ deba ser objeto de publicación en el BOP no debe conducir a pensar que esa DSU sea una norma jurídica (una disposición normativa), como lo son todos los planes urbanísticos, pues la propia LRJPAC ${ }^{101}$ contempla la publicación como uno de los posible modos para que un acto administrativo sea eficaz, precisamente en aquellos casos en que así lo establezcan las normas reguladoras. Ahora bien, dado que las DSUs existentes a la entrada en vigor de la LOUA habían sido elaboradas (normalmente), de acuerdo con el art. 81 TRLS (vigente en Andalucía también después de 1997, por obra de la LAS), y dado que ese precepto permitía que las DSUs contuviesen elementos de ordenación urbanística, ha de interpretarse que las modificaciones de esas DSUs que se lleven a cabo después de la entrada en vigor de la LOUA pueden contener elementos de ordenación, porque esas DSUs conservan su vigencia y ejecutividad y porque la LOUA declara que es de inmediata y directa aplicación (entre otras cuestiones) la nueva clasificación del suelo, pero no la parte relativa a la ordenación urbanística (Título I), que es donde se habla de los instrumentos de ordenación. En esta DSU parece igualmente quebrar el carácter residual del suelo urbano consolidado respecto del no consolidado, pues la LOUA permite que se haga una DSU de suelo consolidado, sin mencionar, sin embargo, si los terrenos urbanos que queden fuera de esa DSU deberán ser reputados necesariamente como no consolidados.

\footnotetext{
${ }^{97}$ Art. 17, 4, LOUA.

${ }^{98}$ DT $1^{a}, 1,1 \stackrel{a}{a}$, letra a, segundo párrafo, LOUA.

${ }^{99}$ ISG, p. 2.

100 Ibidem.

${ }^{101}$ Art. 60 LRJPAC.
} 
Ha de subrayarse que sólo y todos los municipios que dispusiesen de PGOU, NNSS o DSU en el momento de entrada en vigor de la LOUA pudieron - puede aún- redactar con carácter potestativo una DSU, que delimite específicamente el suelo urbano consolidado, y se ha de destacar que es también un derecho de esos municipios; desde esta segunda perspectiva, hay que tomar con reservas la siguiente afirmación de la ISG, a propósito de las DSUs existentes en el momento de entrada en vigor de la LOUA ${ }^{102}$ :

«En resumen, no pueden formularse modificaciones de las DSUs sino lo que procede es fomentar su sustitución por un PGOU».

La reserva con que ha de leerse esa afirmación deriva de que difícilmente podría una ISG, que se aprueba además con carácter orientativo, modificar de forma tan drástica la literalidad de la LOUA, donde, como se sabe, se admite que las DSUs existentes a la entrada en vigor de la LOUA pueden ser objeto de modificación ${ }^{103}$, precisamente para señalar, dentro del perímetro de suelo urbano señalado por la DSU existente, qué terrenos tienen la consideración de suelo urbano consolidado, sin perjuicio, por supuesto, de que al hacer tal cosa se tengan en cuenta, exclusivamente, los criterios señalados en la LOUA $^{104}$, pues el Título II de la LOUA es, desde su entrada en vigor, de aplicación íntegra, inmediata y directa ${ }^{105}$.

En todo caso, ha de tenerse presente que, al derivar de una imposición legislativa hecha con carácter general, las alteraciones que en la clasificación y categorización del suelo derivan de la aplicación inmediata y directa del Título II de la LOUA no dan derecho a indemnización a favor de los propietarios de suelo, es decir, que no es aplicable el art. 41 LRSV.

\section{Vigencia y ejecutividad de los planes e instrumentos vigentes:}

Los Planes e instrumentos vigentes en el momento de entrada en vigor de la LOUA y, específicamente, todos los PGOUs, NNSS o DSUs, que fuesen eje-

102 ISG, p. 8.

${ }^{103}$ DT $1^{a} \stackrel{a}{ }, 1,1 \stackrel{a}{ }$, letra a, párrafo $2^{\circ}$, LOUA.

${ }^{104}$ Los del art. 45, 2, letra A, LOUA, que expresan qué terrenos han de considerarse integrados en el suelo urbano consolidado.

${ }^{105}$ DT $1^{\underline{a}}, 1$, LOUA. 
cutivos en ese momento, conservan su vigencia y ejecutividad, sin perjuicio, por supuesto, de la aplicación de la nueva clasificación de suelo urbano ${ }^{106}$, pero los municipios pueden aprobar adaptaciones totales o parciales de los Planes y restantes instrumentos, es decir, también de las DSUs ${ }^{107}$, lo cual corrobora que los municipios que disponían de una DSU en el momento de entrada en vigor de la LOUA pueden proceder a aprobar una modificación en forma, eso sí, de una DSU del suelo consolidado. Al suelo clasificado como urbano por las DSUs existentes en el momento de entrada en vigor de la LOUA le es de aplicación el régimen que la LOUA establece para esta clase de suelo $\mathrm{y}$, por tanto, debe tenerse en cuenta las dos categorías de suelo urbano y, en consecuencia, lo señalado en los arts. 55 y 56 sobre el régimen de estas dos categorías de suelo urbano; para la aplicación del régimen del suelo urbano no consolidado se tendrá en cuenta el art. 55, 2, LOUA, dado que lo habitual es que no se hayan previsto unidades de ejecución y, en todo caso, no existen áreas de reparto ${ }^{108}$, pero se entiende que si, frente a lo que se considera habitual, se han fijado unidades de ejecución, entonces el régimen aplicable será el del art. 55, 1, LOUA, donde se contiene el régimen jurídico del suelo urbano no consolidado para el que la ordenación urbanística fije o prevea unidades de ejecución. A la luz de estas previsiones ha de acogerse igualmente con reservas la ISG cuando afirma que no será de aplicación a las DSUs vigentes el régimen de innovación que la Ley contempla para los instrumentos de planeamiento ${ }^{109}$; la reserva deriva de que la propia LOUA admite que las DSU se modifiquen y se adapten y, además, no se trata de aplicar a las DSUs las reglas de innovación del planeamiento propiamente dichas, sino, simplemente, las normas de adaptación a la LOUA, que es algo distinto.

\section{Nuevas Delimitaciones de Suelo Urbano en municipios sin planeamiento ge- neral:}

En los municipios que al tiempo de entrada en vigor de la LOUA no contasen aún con planeamiento general, el suelo se entiende clasificado en urbano y no urbanizable, e integran el suelo no urbanizable todos los terrenos que no deban clasificarse como suelo urbano en aplicación de los criterios esta-

\footnotetext{
${ }^{106}$ DT 2ª, 1 , LOUA. Vid., en el mismo sentido, la ISG, p. 8.

${ }^{107}$ DT 2ạ, 2, Párrafo 1, LOUA.

${ }^{108}$ ISG, p. 8.

${ }^{109}$ ISG, p. 8.
} 
blecidos en el art. 45 LOUA $^{110}$. En tales municipios el perímetro del suelo urbano, con distinción del no consolidado, se señalará mediante un Proyecto de DSU, que podrá contener, además, la determinación de las alineaciones del viario existente y de las que sean precisas para corregir sus deficiencias o insuficiencias o para completarlo ${ }^{111}$; el Proyecto de DSU se aprueba inicialmente por el Ayuntamiento Pleno y, previa información pública por al menos veinte días, definitivamente por la Consejería competente en materia de urbanismo; es aplicable a su aprobación definitiva lo dispuesto en la LOUA para los planes de ordenación urbanística ${ }^{112}$.

Tanto si se defiende que las DSUs vigentes en el momento de entrada en vigor de la LOUA son verdaderos planes urbanísticos que contienen ordenación urbanística, como si se niega su carácter de instrumento de planeamiento, esta DT 7ํㅡㄹ no se aplica a los municipios que tuviesen ya una DSU en el momento de entrada en vigor de la LOUA, pues a tales municipios se les aplica la DT $1^{\mathrm{a}}, 1,1^{\mathrm{a}}$, letra a, segundo párrafo, cuyo contenido ya he analizado. La ISG aclara que cuando las DSUs aprobadas en municipios sin planeamiento general contienen determinaciones para corregir las deficiencias o insuficiencias del viario, estamos ante unas «propuestas de ordenación y gestión» ${ }^{113}$, lo

${ }^{110} \mathrm{DT} 7^{\mathrm{a}}$, párrafo primero, LOUA, a la que remite la DT $1^{\mathrm{a}}, 1,1^{\mathrm{a}}$, letra e, LOUA. En los municipios que carezcan de planeamiento general el suelo que no tenga la condición de urbano tendrá la consideración de no urbanizable (art. 11 LRSV). Esta previsión fue impugnada ante el TC, que impuso mediante la STC núm. 164/2001, de 11 de julio, una interpretación conforme con la CE, con las siguientes palabras: «Las reglas de la hermenéutica también permiten concluir que la referencia al "planeamiento general" ha de entenderse hecha -de forma similar a como dijimos en el FJ 8 respecto del término "planeamiento"- a cualquier instrumento de ordenación urbanística que cumple la tarea de clasificación del suelo, llámese ese instrumento de clasificación "plan" (general o no), "proyecto de ordenación", o de cualquier otra forma. De este modo sería posible -conforme a la regulación urbanística de cada Comunidad Autónoma- la existencia de suelo susceptible de transformación o urbanización en virtud de instrumentos de ordenación urbanística distintos de los planes generales. Así interpretado, el art. 11 LRSV es conforme con el orden constitucional de competencias».

${ }^{111}$ DT 7ª̣, párrafo segundo, frases primera y segunda, LOUA.

${ }^{112}$ DT $7^{\mathrm{a}}$, segundo párrafo, frases tercera y cuarta, LOUA. Concretamente, corresponde la aprobación a la Comisión Provincial de Ordenación del Territorio y Urbanismo, de acuerdo con el art. 13, 2, letra b, del Decreto núm. 193/2003, de 1 de julio, por el que se regula el ejercicio de las competencias de la Administración de la Comunidad Autónoma de Andalucía en materia de Ordenación del Territorio y Urbanismo (BOJA núm. 133, de 14 de julio de 2003).

113 ISG, p. 9. 
cual parece aceptar el carácter de planeamiento, al menos de las DSUs que lleven a cabo, tras la LOUA, los municipios que careciesen de planeamiento en el momento de entrada en vigor de la ley, frente a lo que la propia ISG ha afirmado en otro lugar.

En este supuesto, la aprobación definitiva corresponde a la Consejería, precisamente porque se trata de elaborar una DSU en un municipio que no la tenía y porque, además, se permite que la DSU contenga determinaciones no contempladas en la mera modificación de la DSU existente ${ }^{114}$. Quiero reite-

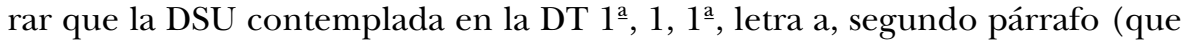
fija el suelo consolidado) es distinta de la DSU contemplada en la DT 7 ${ }^{\mathrm{a}}$, como lo pone de manifiesto la propia terminología, pues en la DT $7^{\underline{a}}$ se habla de Proyecto de DSU, una terminología idéntica a la utilizada en el derecho anterior para referirse a esta figura. De alguna manera la DSU contemplada en la DT $1^{\underline{a}}, 1,1^{\underline{a}}$, letra a, segundo párrafo, no es, propiamente, una DSU -en el sentido tradicional que esta expresión ha tenido en derecho español-, sino, más sencillamente, una mera fijación de los límites del suelo urbano consolidado. También la ISG advierte esa diferencia entre unas DSUs y otras, pues las que se formulan para municipios sin planeamiento son, dice, «más amplias» ${ }^{115}$.

¿Cuál es la razón a que obedece el distinto tratamiento que reciben las DSUs en el derecho transitorio? ¿Por qué de acuerdo con la LOUA un municipio que dispusiese ya de una DSU en el momento de entrada en vigor de la LOUA puede sólo modificar la DSU existente para señalar el suelo consolidado -aunque ya hemos visto que, en puridad, puede contener previsiones adicionales de ordenación-, mientras que el municipio que no dispusiese de ningún planeamiento general en el momento de entrada en vigor de la LOUA puede hacer una DSU, con delimitación del suelo urbano no consolidado, y con determinaciones adicionales? En primer lugar, he de decir que la previsión de la DT 7 no es, en realidad de verdad, una previsión de derecho transitorio, sino que debería haberse incluido en la parte sustantiva de la LOUA. Da la impresión de que a última hora el legislador tuvo en cuenta que Andalucía no es única, sino que hay una gran variedad de situaciones y, en particular, que existen pequeños municipios en la Andalucía oriental, sobre todo de montaña, que no necesitan un PGOU, sino más sencillamente una DSU. Esto lo explica casi todo, pues, en efecto, la DT $7^{\underline{a}}$ no es una verdadera transi-

\footnotetext{
${ }^{114}$ DT 1aa $, 1,1 \underline{a}$, letra a, segundo párrafo, LOUA.

${ }^{115}$ ISG, p. 2.
} 
toria, dado que no atiende a ninguna situación derivada de un planeamiento preexistente, sino a todo lo contrario, es decir, a la situación de los municipios que no tenían ningún planeamiento general ni ninguna DSU (si se niega que la expresión planeamiento general incluya a las DSUs).

Puede existir, a mi juicio, una explicación adicional del distinto tratamiento que las DSUs reciben en el derecho transitorio de la LOUA, una explicación de índole más teórica que práctica, y para cuya comprensión ha de recordarse que el suelo urbano consolidado tiene en la LOUA un cierto carácter residual respecto del suelo urbano no consolidado. El PGOU contemplado en la LOUA habrá de pronunciarse siempre tanto sobre qué terrenos forman parte del suelo urbano consolidado y qué suelos forman parte del suelo urbano no consolidado, pero surge la duda relativa a si en los dos tipos de DSUs contempladas en la LOUA (DSUs en municipios que ya tuviesen PGOU, NNSS o DSU en el momento de entrada en vigor de la LOUA y DSUs en municipios que careciesen de planeamiento general en el momento de entrada en vigor de la LOUA) deben también determinarse siempre y en todo caso qué terrenos, dentro del suelo urbano, forman parte del suelo urbano consolidado y cuáles del suelo urbano no consolidado, es decir, si debe existir un pronunciamiento expreso de la DSU sobre la naturaleza de todos los terrenos delimitados dentro del suelo urbano. Esta parece ser la respuesta si no correcta, al menos la que mayor seguridad jurídica proporciona al propio municipio y a los propietarios. Se plantea, como digo, otra opción, y esta sería si basta, como parece desprenderse de alguna disposición transitoria de la normativa andaluza ${ }^{116}$, que el municipio delimite qué suelo urbano es suelo urbano no consolidado, siendo todos los demás terrenos parte del suelo urbano consolidado o si, por el contrario -como se infiere de alguna otra previsión normativa ${ }^{117}$, debe determinar qué terrenos forman parte del suelo urbano consolidado, siendo todos los demás terrenos parte del suelo urbano no consolidado. En cualquiera de esos dos casos surge la duda, adicionalmente, relativa a si los terrenos no clasificados expresamente como suelo urbano consolidado o como suelo urbano no consolidado, respectivamente, tendrán siempre y necesariamente la condición de suelo urbano no consolidado y consolidado, también respectivamente, es decir, la duda relativa a si la determinación de una u otra categoría de suelo tiene efectos residuales sobre la otra categoría no expresamente determinada. Estas dudas han de resolverse a la luz de lite-

\footnotetext{
${ }^{116}$ DT 7aㅗ LOUA.

${ }^{117}$ DT $1^{\mathfrak{a}}, 1,1^{\mathrm{a}}$, letra a, segundo párrafo, LOUA.
} 
ralidad de la norma y también a la luz de los principios inspiradores del ordenamiento urbanístico, y, en particular, a la luz del principio de no indemnizabilidad de las determinaciones del planeador y, por el contrario, de la indemnizabilidad de las variaciones del planeamiento en determinadas circunstancias; se ha de tener presente que si se determina expresamente sólo el suelo no consolidado, un intento posterior del municipio de considerar como no consolidado el suelo urbano que no fue en su día incluido dentro del no consolidado, habría de reputarse como una variación del planeamiento que da derecho a indemnización; inversamente, la solución no sería la misma, pues si lo que se determina expresamente es el suelo consolidado, el suelo no consolidado que lo es porque no fue en su día categorizado como consolidado, podría sujetarse al régimen jurídico del consolidado, siempre, por supuesto, que, de acuerdo con los criterios de la LOUA ${ }^{118}$, no haya de ser considerado, en todo caso, como no consolidado; en ese supuesto, no habría que indemnizar al propietario, pues desde el punto de vista del aprovechamiento urbanístico la situación del suelo consolidado es mejor que la del no consolidado.

Si se acepta el carácter residual del consolidado respecto del no consolidado puede igualmente aceptarse que existiendo en los municipios que dispusiesen de una DSU en el momento de ser aprobada la LOUA un suelo urbano, sin distinción entre consolidado y no consolidado, si la LOUA no hubiese permitido que en esos municipios los Ayuntamientos procediesen a realizar una DSU con la determinación del suelo urbano consolidado, surgía el riesgo de que todo el suelo clasificado como urbano fuese reputado como suelo urbano consolidado, por aplicación de la regla residual. Se trata sólo, como digo, de una posibilidad o de un riesgo inherente a la propia literalidad de la LOUA, no de una consecuencia ineluctable derivada del modo en que está redactado el precepto que define el suelo urbano consolidado ${ }^{119}$. A la luz de lo anterior, si se acepta el carácter residual del consolidado respecto del no consolidado, parece que hubiese sido más correcto que la LOUA permitiese a los municipios que dispusiesen de una DSU a la entrada en vigor de la LOUA que determinasen no tanto qué suelo es consolidado cuanto qué terrenos, dentro del suelo urbano, tienen la condición de suelo urbano no consolidado, pues si se acepta el carácter residual del suelo urbano consolidado, el resto de suelo urbano que los municipios no hubiesen clasificado como urbano no consolidado, habrían de reputarse, necesariamente, como consolidado. Al permi-

\footnotetext{
118 Art. 45, 2, letra B, LOUA.

119 Art. 45, 2, letra A, LOUA.
} 
tir, por el contrario, que el municipio determine mediante una DSU el suelo que ha de reputarse consolidado podría estar aceptándose que el resto del suelo urbano pueda ser considerado como consolidado o como no consolidado, en función, por supuesto de los criterios del art. 45 LOUA. En este sentido, la DT 1a , 1, 1르, letra a, primer párrafo, termina con una afirmación rotunda: «El resto del suelo clasificado como urbano a la entrada en vigor de esta Ley tendrá la consideración de suelo urbano no consolidado»; sin embargo, esa afirmación se contiene antes del párrafo que permite que los municipios fijen el suelo urbano consolidado mediante una DSU, y surge la duda relativa a si los terrenos que no sean clasificados como suelo urbano consolidado por esa DSU tienen necesariamente que ser considerados como suelo urbano no consolidado. Por el contrario, la LOUA permite a los municipios que no dispusieran de planeamiento general en el momento de entrada en vigor de la LOUA, que elaboren, ex novo, una DSU, en la que se determina todo el perímetro del suelo urbano, con expresa indicación de cuál es el suelo no consolidado, de donde se sigue que el resto del suelo urbano es consolidado, siempre que se acepte el carácter residual del segundo respecto del primero, aunque la ISG ha interpretado -no porque lo imponga estrictamente la LOUA, sino en aras de la seguridad jurídica- que esas DSUs han de categorizar tanto el consolidado como el no consolidado ${ }^{120}$. Es posible que en el caso de los municipios que ya dispusiesen de una DSU a la entrada en vigor de la LOUA, el legislador haya querido ser respetuoso con los derechos adquiridos por los propietarios de suelo urbano, de manera que la modificación de la DSU implique sólo la determinación de qué suelo está consolidado, sin que haya de reputarse que, necesariamente, todo el suelo urbano restante tenga la condición de urbano no consolidado.

En todo caso, en los municipios que no dispongan de planeamiento general es aplicable el art. 57, 2, LOUA, que contiene tres reglas que han de observarse en los actos de construcción o edificación e instalación que se realicen en terrenos adscribibles a la clase de suelo urbano.

\section{Planes urbanísticos aprobados inicialmente:}

Los planes que hubiesen sido aprobados inicialmente en el momento de entrada en vigor de la LOUA continúan tramitándose de conformidad con el derecho anterior a la LOUA, pero deben ajustarse completamente a lo dispuesto en la LOUA sobre el régimen urbanístico del suelo y la actividad de

${ }^{120}$ ISG, p. 9. 
ejecución; esta última previsión, implica que se otorga eficacia inmediata y directa al Título IV de la LOUA, en el caso de esos planes aprobados sólo inicialmente. La ISG prevé que en esos casos la Resolución que recaiga sobre estos PGOU debe incluir una serie de apartados ${ }^{121}$, algunos de los cuales afectan al suelo urbano ${ }^{122}$, como la que establece que los Ayuntamientos deben aprobar en el plazo de seis meses, tras la tramitación correspondiente, una DSU de suelo consolidado. Si los planes no contienen la distinción entre las categorías de consolidado y no consolidado, con independencia de que la Resolución de aprobación definitiva señale la vigencia de la aplicación de esta distinción, los Ayuntamientos deberán complementarlos mediante la redacción y tramitación de una DSU de suelo consolidado. De algún modo, el autor de la ISG está asimilando la situación de los municipios que tuvieran aprobado inicialmente su planeamiento con la de los municipios que ya dispusiesen de planeamiento o de una DSU, pues remite a la DT $1^{\underline{a}}$ en lugar de a la DT 7ª , pero, a mi juicio, si el municipio no tuviese planeamiento alguno, podría, transitoriamente, proceder a aprobar la DSU contemplada en la DT $7^{\underline{a}}$.

\section{CONCLUSIONES}

El derecho transitorio plantea siempre numerosos problemas, particularmente en un ordenamiento como el urbanístico de Andalucía, donde no siempre la LOUA goza de la suficiente claridad en su forma de expresarse y de coherencia entre unas y otras determinaciones.

Uno de los puntos donde la LOUA se mueve en el límite de la constitucionalidad, a la luz de las condiciones básicas estatales que garantizan la igualdad en el ejercicio del derecho de propiedad -tal y como se contienen en la LRSV- es, sin duda, el concepto de suelo urbano no consolidado, en la medida en que la oscuridad con la cual está definida esta categoría podría esconder, en ocasiones, un intento de integrar en esa categoría terrenos que, en puridad, habrían de considerarse íntegramente urbanizados, y, por tanto clasificados como suelo urbano consolidado, de donde, en su caso, podría derivarse la imposición de deberes sobre determinados propietarios -como, singularmente, los deberes de cesión-, no sólo que van más allá de los previstos por la LRSV para los propietarios de suelo urbano consolidado por la urbanización, sino que vulnerarían las condiciones básicas estatales.

\footnotetext{
121 ISG, p. 5.

122 Anexo A de la ISG.
} 
He tratado en la primera parte de distinguir entre suelo urbano, suelo urbanizado, suelo consolidado, suelo no consolidado, terrenos que disponen de determinados servicios y solar, pues al violar el art. 45 las reglas de la lógica, esos conceptos están confusamente abordados. He tratado también de demostrar por qué en la LOUA el suelo urbano consolidado es una categoría residual respecto del suelo urbano no consolidado y conviene que no se altere indebidamente -por vía del derecho transitorio- el cierto carácter residual que puede detectarse en las previsiones sustantivas de la LOUA del suelo urbano consolidado respecto del suelo urbano no consolidado y que ese carácter se tenga en cuenta a la hora de aplicar, en la práctica, las DTs de la LOUA. A pesar de que algunos preceptos de la LOUA pudiesen dar pie a pensar que el suelo urbano consolidado es equivalente al concepto de terreno que tiene la naturaleza de solar edificable, tal cosa no es verdaderamente así, pues de otra forma, y entre otras consecuencias perniciosas de una tal asimilación, se estaría integrando dentro del suelo urbano no consolidado un conjunto de terrenos que gozan ya de urbanización, pero que requiere una simple mejora o reparación.

$\mathrm{Al}$ ya de por si delicuescente tratamiento del suelo urbano en los preceptos consagrados a su definición y al modo en que ha de ser contemplado en el planeamiento, la LOUA añade unas previsiones de derecho transitorio que generan numerosas dudas, algunas de las cuales han sido correctamente aclaradas por la ISG y otras, sin embargo, han sido indebidamente ampliadas. Entre las cuestiones conflictivas destaca la aplicación inmediata y directa de la distinción entre suelo urbano consolidado y suelo urbano no consolidado en relación con las DSUs contempladas en dos de las Disposiciones Transitorias, una relativa a municipios que contasen ya con PGOU, NNSS o DSUs y otra relativa a municipios que no contasen con planeamiento general; una parte de esas dudas se resolvería si se aceptase que la delimitación del suelo urbano consolidado contemplado en la primera de esas DTs no es, propiamente, una de las DSU que el derecho urbanístico español ha venido regulando desde 1976, pero ha de subrayarse que dado que las DSUs existentes a la entrada en vigor de la LOUA habían sido elaboradas (normalmente), de acuerdo con el art. 81 TRLS (vigente en Andalucía también después de 1997, por obra de la LAS), y dado que ese precepto permitía que las DSUs contuviesen elementos de ordenación urbanística, ha de interpretarse que las modificaciones de las DSUs que se lleven a cabo después de la entrada en vigor de la LOUA, de acuerdo con la DT 1aa 1 , 1 $1^{\underline{a}}$, letra a, segundo párrafo, pueden contener elementos de ordenación, porque esas DSUs conservan su vigencia y ejecutividad y porque la LOUA declara que es de inmediata y directa aplicación (entre otras cuestiones) la nueva clasificación del suelo, pero no la parte relativa a la ordenación urbanística (Título I), que es donde se habla de los instrumentos de ordenación o planeamiento. 